\title{
A implantação da saúde bucal no programa consultório na rua em Curitiba-PR
}

\section{The implementation of oral health in the street consulting program in Curitiba-PR}

\section{La implementación de la salud oral en el programa de consultoría de calle en Curitiba-PR}

Rebeca Alves Lins de Albuquerque ${ }^{1}$ Anna Cristina da Silva Nascimento ${ }^{1}$

Rosane Souza Freitas

Adriane Wollmann

Ruann Oswaldo Carvalho da Silva

Rafael Gomes Ditterich

RESUMO: população em situação de rua, ao longo dos anos, sofreu um processo de exclusão social, que os impossibilitou o acesso ao sistema de saúde de forma convencional, seja por falta de documentos de identificação, falta de sensibilidade da equipe ou a inabilidade de um único local em atender à variedade de problemas apresentados pelos moradores de rua. Também vale ressaltar que essa população apresenta diversas demandas e necessidade de saúde acumuladas, destacando dentre elas os problemas de saúde bucal. Deste modo, o presente estudo tem como objetivo relatar a experiência da inclusão da saúde bucal no Programa Consultório na Rua (PCR) de CuritibaPR. Para atingir tal finalidade utilizou-se de pesquisa documental e entrevista semiestruturada para análise qualitativa dos dados. Concluiu-se que a inclusão de profissionais da saúde bucal na equipe multiprofissional do Programa Consultório na Rua tem sido de fundamental importância, pois permite estreitamento do vínculo e maior adesão ao tratamento por parte da população em situação de rua. A experiência de Curitiba-PR tem revelado que a aproximação da saúde bucal a população em situação de rua, é um importante fator no resgaste da autoestima e reinserção social dessa população.

Palavras-chave: Consultório na Rua. Política de Saúde. População em situação de Rua.

ABSTRACT: Homeless people have been suffering, throughout the years, a process of social exclusion, which prevented them from having access to the conventional health system, due to

1 Universidade Federal do Paraná

ISSN 1982-8829 Tempus, actas de saúde colet, Brasília, 13(3), 191-200, set, 2019. Epub Jul/2020 
lack of identification documents, team insensitivity or absence of places capable to meet all needs shown by homeless people. Besides, homeless people have many accumulated health problems, highlighting oral health issues. Thereby, the aim of this study is to describe the oral health team inclusion in the "Street Office Program" in Curitiba - PR. To achieve this aim, documental researches and interviews were made for the data qualitative analysis. It was concluded that the inclusion of an oral health team to the program is fundamental, once it allows bond narrowing and greater adherence to the treatment. The experience in Curitiba-PR has been showing that the improvement of oral health in these people is essential to rescue their self esteem and assure social reinsertion.

Key Words: Consultation office in the street. Health policy. Population in street situation.

RESUMEN: La población sin hogar, a lo largo de los años, sufrió un proceso de exclusión social, lo que les impidió acceder al sistema de salud de manera convencional, ya sea por falta de documentos de identificación, falta de sensibilidad del personal o la incapacidad de un Lugar único para abordar la variedad de problemas experimentados por las personas sin hogar. También es digno de mención que esta población tiene varias demandas y necesidades de salud acumuladas, destacando entre ellas los problemas de salud bucal. Por lo tanto, este estudio tiene como objetivo informar la experiencia de la inclusión de la salud oral en el Programa de Clínica de la Calle (PCR) Curitiba-PR. Para lograr este propósito, utilizamos la investigación documental y las entrevistas semiestructuradas para el análisis de datos cualitativos. Se concluyó que la inclusión de profesionales de la salud oral en el equipo multiprofesional del Programa de la Clínica de la Calle ha sido de fundamental importancia, ya que permite lazos más estrechos y una mayor adherencia al tratamiento por parte de la población sin hogar. La experiencia de Curitiba-PR ha revelado que la aproximación de la salud bucal a la población sin hogar es un factor importante en la recuperación de la autoestima y la reintegración social de esta población.

Palabras clave: Clínica callejera. Política de salud Población sin hogar

\section{INTRODUÇÃO}

A população em situação de rua (PSR) consiste em um grupo heterogêneo, com indivíduos das mais diversas faixas etárias, de ambos os sexos e com diversidade de enfermidades.A definição de pessoa em situação de rua é extremamente complexa, mas de acordo com Teixeira e Fonseca $(2015)^{1}$ e o decreto 7.053 de dezembro de $2009^{2}$ - que instituiu a Política Nacional para População em Situação de Rua - pode-se definir população de rua comoum grupo heterogêneo de pobreza extrema, com vínculos familiares interrompidos,sem moradia, que utiliza logradouros públicos como moradia e sustento de forma temporária ou permanente, também utiliza as unidades de acolhimento para pernoite temporário oumoradia provisória.

O Brasil ainda não conta com dados oficiais sobre a população em situação de rua.A pesquisa nacional mais recente sobre PSR foi divulgada em 2016, realizada pelo Instituto de Pesquisa Tempus, actas de saúde colet, Brasília, 13(3), 191-200, set, 2019. Epub Jul/2020 ISSN 1982-8829 
Econômica Aplicada (IPEA) ${ }^{3}$. O estudo apresenta uma estimativa de pessoas em situação de rua em todo o Brasil. Segundo a pesquisa, considera-se que em 2015 o número da PSR no país era de 101.854 pessoas. Deste total, calcula-se que em média 40,1\% dos sujeitos habitem em municípios com mais de 900 mil habitantes, e 77,02\% vivem em municípios com mais de 100 mil habitantes ${ }^{3}$.

Em setembro de 2005, a Secretaria Nacional de Assistência Social (SNAS) realizou o I Encontro Nacional sobre População em Situação de Rua, no qual foram debatidos, em conjunto com os movimentos representativos desse segmento social, os desafios, as estratégias e as recomendações para a formulação de políticas públicas nacionais para essa parcela da população. Como prioridade, foi destacada a importância da realização de estudos que possam os caracterizar socioeconomicamente, de modo a orientar a elaboração e implementação de políticas públicas direcionadas a tal público ${ }^{4}$.

O significado do processo saúde-doença para este grupo também é diferenciado. As pessoas em situação de rua tendem a fazer uma avaliação positiva de sua condição de saúde ${ }^{5}$. Entretanto, a PSR normalmente se reporta ao serviço de saúde em situações emergenciais, não reconhecendo o seu corpo doente até que o sintoma paralise as suas atividades diárias ${ }^{6}$.

Os problemas de saúde mais encontrados na Pesquisa Nacional sobre Pessoas em Situação de Rua foram: Hipertensão (10,1\%), problemas psiquiátricos/mental (6,1\%), HIV/AIDS $(5,1 \%)$ e problemas de visão/cegueira $(4,6 \%)^{4}$. Além dos já citados, o abuso de substâncias psicoativas, problemas odontológicos, dermatológicos e gastrointestinais também podem ser encontrados ${ }^{5}$.

Tendo em vista as carências desta população, a dificuldade de acesso aos programas assistenciais e ao Sistema Único de Saúde(SUS), foi criado em 2011 o Programa Consultório na Rua (PCR) ${ }^{7}$, que busca atender este grupo de forma integral,guiando-se pelos princípios e diretrizes do SUS. O PCR é um dispositivo valioso na luta pela efetivação de um SUS mais equânime e universal. Porém, por ser umaestratégia recente, existe pouco estudo sobre o tema, seja na esfera nacional ou retratando as experiências locais ${ }^{8}$.

Em Curitiba-PR, o PCR foi implementado em 2013 e possui desde seu início a proposta de equipe multiprofissional integrando o serviço, sendo considerada uma referência nacional como política de saúde para PSR ${ }^{9,10}$. A Secretaria Municipal da Saúde de Curitiba (SMS Curitiba) possui quatro equipes de Consultório na Rua (eCR), formadas por médicos, psicólogos, enfermeiros, auxiliares de enfermagem, assistentes sociais, cirurgiões-dentistas e auxiliares de saúde bucal que, diariamente e de forma itinerante, percorrem ruas, praças e pontos estratégicos da cidade $^{10}$.

O município de Curitiba-PR possui hoje 10 distritos sanitários. As eCR dividem-se em quatro macrorregiões da cidade, a área de atuação é definida levando-se em consideração a estimativa de um censo que considera variáveis de crescimento demográfico, centralidade e dinamismo urbano, vulnerabilidade social e serviços voltados à população de rua, número de pessoas em situação de rua cadastradas no Cadastro Único para programas sociais do governo federal ${ }^{11}$. 
Deste modo, o presente estudo teve como objetivo relatar a experiência da inclusão da saúde bucal no Programa Consultório na Rua (PCR) de Curitiba-PR.

\section{MATERIAIS E MÉTODO}

Com o intuito de apreender questões relacionadas à inclusão da saúde bucal no PCR de Curitiba-PR, optou-se neste estudo pelo desenvolvimento do método qualitativo, por meio de dados primários e secundários. As técnicas para coleta de dados foram a pesquisa documental e a entrevista semiestruturada.

A pesquisa documental foi realizada a partir de matérias em mídia televisiva, impressa e digital, bem como de arquivos públicos. As diferentes mídias e documentos foram obtidos mediante pesquisa na internet, ou de documentos internos, que foram fornecidos pela SMS Curitiba.

No que tange às entrevistas semiestruturadas, os sujeitos entrevistados pertenciam a três grupos, sendo eles: gestão ( 1 entrevistado), profissionais da saúde, como enfermeiros, técnicos de enfermagem, técnico em saúde bucal e cirurgiões-dentistas (22 entrevistados) e representantes da população atendida pelo programa que compõem o Movimento Nacional da População em Situação de Rua (MNPR)- 4 entrevistados.

Foram considerados como critérios de inclusão para o estudo: gestor, que tivesse participado do processo de implementação do Consultório na Rua (CR) e da atual gestão do programa; profissionais de saúde, que compunham à equipe do CR desde o início da sua implementação, englobando os de nível médio e superior, e que no momento da pesquisa não estivessem de férias, licença, ou exercendo alguma função fora do CR, ainda que pertinente ao serviço; e os integrantes do MNPR que tivessem participado do programa desde o início do CR, sendo estes identificados como informantes de grande relevância. De forma geral, foram inseridos todos aqueles que estavam no perfil delimitado e que consentiram em participar livre e voluntariamente da pesquisa. Assim, a amostragem foi intencional, visto que se buscaram propositalmente aqueles sujeitos com características pertinentes ao estudo ${ }^{12}$.

Para o método qualitativo, optou-se pela análise de conteúdo, que consiste em um conjunto de instrumentos metodológicos etécnicas de análise das comunicações que utiliza procedimentos sistemáticos e objetivos de descrição do conteúdo das mensagens ${ }^{13}$.

O estudo atendeu aos fundamentos e princípios éticos e científicos, garantindo assim o respeito aos participantes da pesquisa, sendo aprovado pelo Comitê de Ética em Pesquisa sob o parecer CEP/ SD-PB n ${ }^{\circ}$ 969209. Preservando a integridade e a privacidade dos dados envolvidos na pesquisa, sendo os mesmos utilizados apenas para estudos e publicações que envolvam os interesses da área. Enfatiza-se que os aspectos éticos foram fundamentados na Resolução no 466/2012, que dispõe sobre normas regulamentadoras de estudos envolvendo seres humanos ${ }^{14}$. 


\section{RESULTADOS E DISCUSSÃO}

De acordo com o projeto de implantação do CR de Curitiba-PR que foi encaminhado, apresentado e aprovado pelo Conselho Municipal de Saúde, em 2013, o município deveria contar com três equipes na modalidade III e uma equipe da modalidade II. Com a divulgação da Portaria $n^{\circ} 2.517$, de 11 de novembro de $2014^{15}$, que alterou as modalidades de eCR, o município de Curitiba-PR passou a contar com 3 eCR na modalidade II e 1 eCR na modalidade III.

Dentre os profissionais que compõem desde o início de forma diferenciada as eCR em CuritibaPR, estão: 3 assistentes sociais, 2 cirurgiões-dentistas, 3 enfermeiros, 2 médicos, 4 psicólogos, 10 técnicos ou auxiliares de enfermagem e 3 auxiliares de saúde bucal.Totalizando 27 profissionais, além da coordenadora da gestão do CR.

A SMS Curitiba desde a implantação do PCR percebeu a necessidade do atendimento odontológico, e incluiu os cirurgiões-dentistas e auxiliares de saúde bucal de maneira pioneira, pois nas portarias 122 e 123 de 2011 e 2012 (respectivamente) ${ }^{7,11}$ não havia a obrigatoriedade de cirurgião-dentista,e diferentemente das portarias supracitadas, Curitiba-PR possui auxiliar de saúde bucal. O relato da coordenadora do PCR, em publicação institucional, evidencia o porquê da inclusão da saúde bucal na eCR em Curitiba-PR:

“(...) como já tínhamos uma experiência anterior no atendimento à população em situação de rua, sabíamos da importância de contar com cirurgiões-dentistas nas equipes, até mesmo para o estreitamento do vínculo com o morador de rua. Mesmo sem estar previsto na portaria anterior do Ministério da Saúde, a Secretaria resolveu assumir os custos para prestar um atendimento ainda mais qualificado para essa população" (WOLLMANN, 2014)

Segundo exposto pelo então Coordenador Nacional de Saúde Bucal de 2014, a experiência de Curitiba-PR motivou a possibilidade da inclusão de profissionais da saúde bucal na portaria n. 1.029 de $2014^{16}$ :

"Curitiba teve uma experiência exitosa com a implantação dos cirurgiõesdentistas no Consultório na Rua. É um profissional que facilita o acesso e o vínculo a essa população. A saúde é um exemplo de equidade e, quanto mais frentes tivermos para chegar à população em situação de rua, melhor." (PUCCA, 2014).

Como explicitado, a saúde bucal permite a associação da equipe multiprofissional com o indivíduo em situação de rua, já que os problemas bucais muitas das vezes são os fatores motivadores dessa população para se aproximarem das eCR que estão atuando nas ruas. Grande parte das pessoas em situação de rua apresentam necessidades de atenção em saúde bucal.

“[...] sempre comento assim que eu acho a odonto bem porta de entrada pro CR, ISSN 1982-8829 Tempus, actas de saúde colet, Brasília, 13(3), 191-200, set, 2019. Epub Jul/2020 
bem porta de entrada... desde o começo quando a gente ia em algum, em algum local assim... e os profissionais se apresentavam, quando falava: [...] 'ai eu sou dentista'... de cara o pessoal já ia abrindo a boca: 'ai eu to com esse dente aqui, ta me incomodando, ta doendo'... então acho a odonto super porta de entrada pro consultório, porque todo mundo tem, nem que seja uma limpeza pra fazer, né... todo mundo quer melhorar a autoestima, quer arrumar o dente da frente, as vezes ta achando que ta esbarrando ali pra uma entrevista de emprego, então é bem porta de entrada... [...] muito bem aceita" (ENT12).

“[...] E outra coisa que chama muito minha atenção também é a odonto né, porque às vezes eu brinco [...] num atendimento ele ganha o céu né, porque ele alivia a dor na hora, imediatamente... é... acho que ele conquista muito o paciente pelo alívio da dor, que é imediato. [...] muito bacana o trabalho da odonto. [...] acho que é um diferencial importante" (ENT15).

O pioneirismo da inclusão em Curitiba-PR, fez com que os profissionais de saúde bucal repensassem sua atuação, colocando a rua como cenário de prática no cuidado em saúde bucal, como exemplificado pela fala de um dos entrevistados:

“Aqui em Curitiba nós atuamos um período em área, vendo local onde os moradores de rua moram, realizando atendimentos no local mesmo e atendimentos dentro da clínica odontológica das unidades onde nós conseguimos espaço" (ENT10).

Em Curitiba-PR, os dois cirurgiões-dentistas trabalham na rua com identificação e prevenção de necessidades de saúde bucal do indivíduo em situação de rua, os casos cuja resolução necessitam de atendimento a nível ambulatorial, são agendados e encaminhados para as Unidades Básicas de Saúde (UBS), onde o atendimento é realizado pelos profissionais da equipe Consultório na Rua, as UBS são utilizadas de ponto de apoio, e quando necessário realizam a referência para a atenção especializada. Destaca-se, noentanto, a resolutividade na necessidade e instalação de prótese total, já que os próprios cirurgiões-dentistas da eCR fazem esse atendimento.

A criação de vínculo também tem sido um diferencial e um passo muito importantes, pois o encontro acolhedor pode ser um "produtor potencial de saúde" ${ }^{17}$, no início os moradores se escondiam sem entender direito o que a equipe queria, tinham medo. Com o passar do tempo foram entendendo que essas equipes estavam lá para ajudar e assim que chegavam à população ia se aproximando para receber atendimento, conhecer a realidade deles facilita a continuidade do atendimento.

A aproximação e vínculo dos profissionais da saúde bucal com a população em situação de rua acaba provocando encontros que facilitam a atenção à saúde bucal, rompendo barreiras como o medo, a dor e a dificuldade de acesso que essa população enfrenta em outros serviços de saúde: 
“(...) muitos moradores de rua tem medo da odontologia. Uma das primeiras demandas que surgem são os problemas dentários, são os problemas da boca (...) mas eles tem medo de dentista, então quando nós vamos lá e avaliamos numa praça, numa rua: Senhor, você precisa concertar esse dente, tem condições de fazer esse tratamento no teu dente. Daí quando a gente fala o horário que poderia ir, o dia e a hora que ele poderia ir, ele fala: ah mas não sei se vou. Eu falo assim: mas sou eu mesmo que vou te atender, e eu vou que tar te esperando lá, não é outra pessoa. - Ah, então eu vou” (ENT10).

Alguns autores ${ }^{18,20-21}$ destacam a potência dessa interação que pode ser percebida não só em aspectos biológicos, relacionados ao cuidado, prevenção e tratamento de doenças, mas em especial na formação de vínculo e resgate da autoestima desses usuários.

"A odontologia traz autoestima, então eles chegam com os dentes cariados, precisando fazer uma profilaxia, tudo manchado, então assim, com dor... porque eles não tem o cuidado com a escovação né, esquecem na verdade né... e chegam com dor, então assim, eles saem do dentista bem mais aliviado, sem dor. Uma vez um paciente falou assim... chegou morrendo de dor, daí extraiu o dente e falou assim: -Nossa, muito obrigado, eu nunca me senti tão bem na minha vida, porque tirou essa dor... tanto tempo tava com dor e ninguém atendia. [...] Então traz autoestima porque eles saem feliz, eles saem mais contente" (ENT11).

A atuação da saúde bucal também provoca mudanças no estilo de vida, principalmente na reintegração social, como identificado em relato por um dos entrevistados:

"[...] um morador de rua que era alcoolista, e tinha diabetes, tinha pressão alta, é... ele veio buscando atendimento... ele perdeu todos os dentes superiores por problemasperiodontais. [...] os dentes todos moles, superiores né... e ele precisava remover todos os dentes. Então tivemos que fazer o acompanhamento com médico, ele é hipertenso, diabético, a cicatrização difícil... mas fizemos o atendimento dele, removemos todos os dentes que eram necessários removê-los, superiores... e tratamos os inferiores que era possível. E na sequência nós fizemos uma prótese total pra ele . E hoje ele não é mais morador de rua, através disso daí... a partir do momento que ele colocou os dentes, ele foi em busca de ajuda pra montar um ponto de venda... [...] E ta bem, ta se sustentando com isso, mora numa pensão, ta se reaproximando da família e não bebe, e ta sorrindo muito" (ENT10).

O identificado, corrobora a Costa et al. $(2014)^{18}$, no qual se destaca que a inclusão da saúde bucal nas eCR tem estimulado a reinserção social das pessoas em situação de rua, tanto na família quanto no mercado de trabalho, após a realização do tratamento odontológico.As questões de saúde bucal afetam não apenas a saúde física dos usuários, como também a saúde emocional, com a queda da autoestima. A falta de dentes pode ser responsável pela dificuldade de encontrar alguma 
possibilidade de emprego, ainda que informal ${ }^{19}$. Como pode ressaltado por alguns entrevistados do estudo.

Um ganho na atenção à saúde bucal, foi a conquista de um odontomóvel para eCR em Curitiba com recurso do Ministério da Saúde:

"Uma novidade que nós temos pra Curitiba é o odontomóvel. Odontomóvel é uma van equipada com uma cadeira odontológica, com os equipamentos odontológicos, inclusive com raio X, com autoclave, que está sendo preparada pra sair pras ruas. [...] Tem algumas regiões da cidade onde a população de rua não tem acessado os serviços da odontologia, nós poderemos nos dirigir até esses locais pra poder fazer o atendimento dessa população" (ENT10).

“[...] O odontomóvel pra odontologia vai ser uma das melhores formas de acesso. A função nossa é acesso e vinculo. Tem pessoas que não acessam a unidade de saúde de jeito nenhum, ou por preconceito dela mesmo, ou por preconceito dos outros, ou porque o tempo dela, de você pedir pra ela vim outro dia, na semana que vem... daí o compromisso de hoje não é o mesmo compromisso de amanhã. Então quando você tem o odonto móvel ali você vai pegar uma outra população que não ta se conseguindo acessar por enquanto. Eu acho que vai ser um ganho também. [...] Vai ser bom, porque daí até uma das questões da gente não ter onde atender, no odonto móvel vai ter né. [...]"(ENT13).

Como apresentado neste estudo, ressalta-se a importância de repensar o processo de trabalho da odontologia, principalmente com a inclusão na eCR, a necessidade de ressignificar o cuidado em saúde bucal em novas práticas integradoras e resolutivas que respeitem e garantam os princípios da equidade e universalidade do SUS a todo tipo de população, principalmente aquelas mais vulneráveis e que muitas vezes são negligenciadas pelas políticas de saúde.

\section{CONSIDERAÇÕES FINAIS}

A inclusão de profissionais de saúde bucal na equipe multiprofissional do Programa Consultório na Rua é de fundamentalimportância, pois permite estreitamento do vínculo e maior adesão ao tratamento por parte da população em situação de rua.

A experiência de Curitiba-PR tem revelado que a aproximação da saúde bucal à população em situação de rua, tem sido um fator importante no resgaste da autoestima e reinserção social dessas pessoas. 


\section{REFERÊNCIAS}

1. Teixeira M, Fonseca Z. Saberes e práticas na atenção primária à saúde: cuidados à população em situação de rua e usuários de álcool, crack e outras drogas. 263 p, São Paulo: Hucitec, 2015.

2. Brasil. Decreto $n^{0} 7053$, de 23 de dezembro de 2009. Institui a PolíticaNacional para a População em Situação de Rua e seu Comitê Intersetorialde Acompanhamento e Monitoramento, e dá outras providências. DiárioOficial da União, Brasília, 23 de dezembro de 2009.

3. Instituto de Pesquisa Econômica Aplicada. Estimativa da População em Situação de Rua no Brasil. 2016 [Internet]. Disponível em: http://www.ipea.gov.br/portal/images/stories/PDFs/ TDs/26102016td_2246.pdf

4. Brasil. META - Instituto de Pesquisa de Opinião Secretaria de Avaliação e Gestão da Informação Ministério do Desenvolvimento Social e Combate à Fome. Pesquisa Nacional Sobre a População em Situação de Rua. Brasília - DF, 2008.

5. Aguiar MM, Iriart JAB. Significados e práticas de saúde e doença entre a população em situação de rua em Salvador, Bahia, Brasil. Cad. Saúde Pública, Rio de Janeiro - RJ, v. 28, n.01, p. 115-124, 2012.

6. Brasil. Ministério da Saúde - Secretaria de Atenção à Saúde. Departamento de Atenção Básica. Manual sobre o cuidado à saúde junto a população em situação de rua. Brasília, DF, 2012.

7. Brasil. Ministério da Saúde. Portaria $n^{\circ} 122$, de 25 de janeiro de 2011. Define as diretrizes de organização e funcionamento das Equipes de Consultório na Rua. Diário Oficial da União, Brasília - DF, 2011.

8. Brasil. Presidência da República. Casa Civil. Decreto n. 7.053, de 23 de dezembro de 2009. Institui a Política Nacional para a População em Situação de Rua e seu Comitê Intersetorial de Acompanhamento e Monitoramento, e dá outras providências, Brasília - DF, 2009.

9. Kami MTM, Larocca LM, Chaves MMN, Piosiadlo LCM, Albuquerque GS. Tool and ideological knowledge in Street Outreach Office working process. Rev Esc Enferm USP; v. 50, n.3, p. 440-447, 2016.

10. Wollmann A, Massuda A, Neto PP, Ros C, LowenIMV. O cuidadoem saúde da população em situação de rua. In: Moysés SJ,Silveira Filho AD. A gestão participativa na saúde de Curitiba / organizado por Curitiba: Instituto Municipal de Administração Pública, 2016.

11. Brasil. Ministério da Saúde. Portaria n ${ }^{0}$ 123, de 25 de janeiro de 2012. Define os Critérios de Cálculo do Número Máximo de Equipes de Consultório na Rua (eCR) por Município. Diário ISSN 1982-8829 Tempus, actas de saúde colet, Brasília, 13(3), 191-200, set, 2019. Epub Jul/2020 
Oficial da União, Brasília - DF, 2012 b.

12. Turato ER. Métodos qualitativos e quantitativos na área da saúde: definições, diferenças e seus objetos de pesquisa. Revista Saúde Pública. 2005.

13. Bardin L. Análise de conteúdo (L. de A. Rego \& A. Pinheiro, Trads.). Lisboa - Portugal; Edições 70, 2006 (Obra original publicada em 1977).

14. Brasil. Conselho Nacional de Saúde. Resolução n 466, de 12 de dezembro de 2012. Normas Regulamentadoras que dispõe sobre os estudos em seres humanos. Brasília - DF,2012.

15. Brasil. Ministério da Saúde. Portaria n ${ }^{0}$ 2.517, de 11 de novembro de 2014. Credencia Municípios a receberem incentivos referentes às equipes de Consultório na Rua, que compõe o Bloco da Atenção Básica. Diário Oficial da União, Brasilia - DF,2014.

16. Brasil. Ministério da Saúde. Portaria nº 1029, 20 de maio de 2014. Amplia o rol das categorias profissionais que podem compor as Equipes de Consultório na Rua em Suas Diferentes Modalidades e dá outras providências. Diário Oficial da União, Brasília - DF, 2014.

17. Hallais JAS, Barros N.F. Consultório na Rua: visibilidades, invisibilidades e hipervisibilidade. Cad. Saúde Pública, Rio de Janeiro, v.31, n.7, p.1497-1504, 2015.

18. Costa JP, Jorge MSB, Vasconcelos MGF, Paula ML, Bezerra IC. Resolubilidade do cuidado na atenção primária: articulação multiprofissional e rede de serviços. Saúde Debate, Rio de Janeiro, v. 38, n. 103, p. 733- 743, out./dez., 2014.

19. McErlain M, Newton T, Jeremiah HG. Does Dental Appearance Affect Employment Prospects: A Prospective Cross-sectional Study. J Orthod. 2018 Jun;45(2):71-78.

20. Engstrom EM, Teixeira MB. Equipe "Consultório na Rua" de Manguinhos, Rio de Janeiro, Brasil: práticas de cuidado e promoção da saúde em um território vulnerável. Ciênc. saúde coletiva, Rio de Janeiro, v. 21, n. 6, p. 1839-1848, June 2016.

21. Silva LMA, Monteiro IS, Araújo ABVL.Saúde bucal e consultório na rua: o acessocomo questão central da discussão. Cad. Saúde Colet., 2018, Rio de Janeiro, 26 (3): 285-291.

Artigo apresentado em outubro de 2019 Artigo aprovado em janeiro de 2020 Artigo publicado em julho de 2020 